\title{
INFLUÊNCIA DA FONTE DE SÍLICA NA ESTABILIDADE DA CTA-MCM-41 UTILIZADA EM TRANSESTERIFICAÇÃO CATALÍTICA
}

\author{
I. W. ZAPELINI, P. P. MODESTO, L. L. da SILVA, A. F. Campos e D. CARDOSO ${ }^{1}$ \\ Universidade Federal de São Carlos, Departamento de Engenharia Química \\ Laboratório de Catálise - 135565-905 - São Carlos - SP \\ E-mail: iagozapelini@gmail.com, dilson@ufscar.br
}

\begin{abstract}
RESUMO - Dentre os catalisadores heterogêneos utilizados na reação de transesterificação, principal rota de obtenção do biodiesel, estão as sílicas mesoporosas com propriedades básicas. Um material bastante promissor é a peneira molecular MCM-41 contendo cátions orgânicos em sua estrutura. Este trabalho apresenta os resultados da avaliação catalítica da MCM-41 sintetizada com diferentes tipos de fonte de sílica, mostrando como varia a sua estrutura com o reuso do catalisador na reação de transesterificação.
\end{abstract}

\section{INTRODUÇÃO}

A busca por catalisadores heterogêneos para a reação de transesterificação ocupa importante papel no cenário científico. A produção de biodiesel motiva a busca por materiais catalíticos mais ativos e estáveis na rota de obtenção desse biocombustível.

Os materiais com sítios básicos são os mais utilizados, pois permitem operação em condições mais brandas (Gergogianni et al., 2009). Como exemplo, podemos citar a peneira molecular mesoporosa MCM-41 (Gómez et al., 2013). Sua atividade catalítica está ligada a presença de cátions de compensação dos grupos silóxi na estrutura da sílica. Os cátions mais utilizados na síntese desse material são os de amônio quaternário, como na maior parte dos casos, o cetiltrimetilamônio (CTA) (Fabiano et al., 2010).

A lixiviação desses cátions pelo álcool presente no sistema reacional diminui a atividade catalítica da peneira molecular utilizada. Uma das maneiras de melhorar a atividade e estabilidade do catalisador, portanto, é encontrar um cátion orgânico que possua maior interação com a parede de sílica, e então, lixivie menos durante o processo de reuso (Fabiano et al., 2010).

Testes de reuso desse material na reação de transesterificação apresentaram uma diminuição gradativa dos picos de difração, até perda da estrutura típica da MCM-41.Porém, quando a fonte de sílica utilizada é o Aerosil, os picos de difração aumentam. Em seu trabalho, Fabiano (2010) mostrou que durante o reuso da MCM-41 sintetizada com Aerosil, os poros são desobstruídos e a quantidade de material orgânico na estrutura da sílica diminui, 
sugerindo que o aumento dos picos de difração nesse caso são explicados pela absorção de raios-X pelos cátions orgânicos, que diminuem ao longo do reuso por serem lixiviados.

Em seu trabalho, Igarashi et al. (2003) demonstrou que a estabilidade hidrotérmica da MCM-41 está intimamente relacionada com a fonte de sílica utilizada na síntese e também com a temperatura na qual o material é sintetizado. Materiais sintetizados a temperaturas mais elevadas ou com sílica pirolisada apresentaram maior estabilidade que aqueles obtidos com ortossilicato de tetraetila (TEOS).

Este trabalho apresenta resultados da estabilidade estrutural da MCM-41 sintetizada com TEOS (em dois tempos de síntese e temperatura) e trissilicato de sódio, comparando os difratogramas de raios- $\mathrm{X}$ dos materiais ao longo do reuso como catalisadores na reação de transesterificação.

\section{MATERIAIS E MÉTODOS}

\subsection{Síntese dos materiais}

Para a síntese da MCM-41 utilizando TEOS, o procedimento adotado neste trabalho foi o realizado por Schumacher et al. (1999), na presença do surfactante catiônico cetiltrimetilamônio [CTA]. Foram sintetizados dois materiais, um com tratamento hidrotérmico de $2 \mathrm{~h}$ a $30^{\circ} \mathrm{C}$ (TEOS $-2 \mathrm{~h} 30$ graus) e outro de $24 \mathrm{~h}$ a $80^{\circ} \mathrm{C}$ (TEOS $-2 \mathrm{~h} 30$ graus).

Para a síntese com trissilicato de sódio, utilizou-se o método descrito por Mokhonoana e Coville (2010), modificando o tempo de tratamento hidrotérmico para $24 \mathrm{~h}$ a uma temperatura de $80^{\circ} \mathrm{C}$; o material obtido é chamado TRISSILICATO - $24 \mathrm{~h} 80$ graus.

Todos os materiais foram caracterizados por difratometria de raios-X.

\subsection{Avaliação catalítica dos materiais sintetizados}

Os materiais sintetizados foram avaliados cataliticamente em uma reação modelo de transesterificação de monoéster, utilizando como reagentes o metanol e o acetato de metila, numa proporção $2: 1$, durante 30 minutos a $50^{\circ} \mathrm{C}$. Foram utilizados $4 \%$ em massa do catalisador na mistura reacional (Fabiano, 2010).

Para avaliar a estabilidade, após o primeiro uso na catálise, o material foi removido do meio reacional via filtração e foi utilizado novamente. O procedimento catalítico descrito foi realizado 4 vezes. Foi realizada difratometria de raios-X do material após cada uso, para verificar o efeito do reciclo na estrutura da sílica e comparar os materiais sintetizados com sílicas diferentes.

\section{RESULTADOS E DISCUSSÃO}

A Figura 1 mostra os difratogramas de raios-X dos materiais sintetizados. Em ambos casos, obteve-se difratograma típico da MCM-41 (Fabiano, 2010), indicando a formação da fase desejada. Nota-se que o material sintetizado com TEOS, com $2 \mathrm{~h}$ de tratamento 


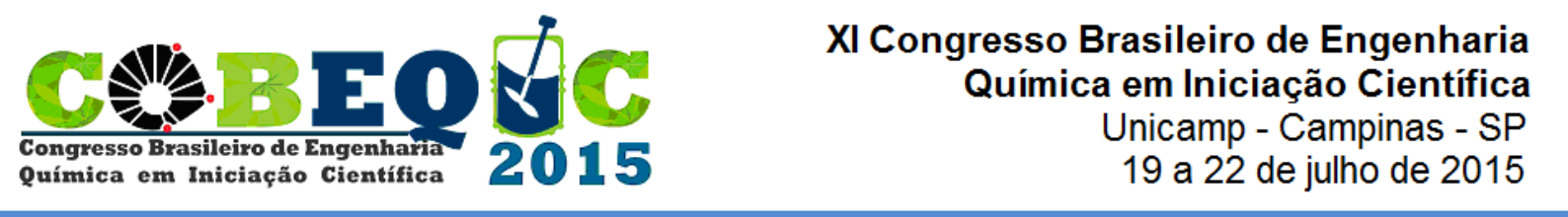

hidrotérmico apresenta picos de difração mais intensos, indicando maior grau de organização do material. A baixa intensidade dos picos da MCM-41 sintetizada com trissilicato de sódio pode ser explicada pelo tempo de tratamento hidrotérmico reduzido de $48 \mathrm{~h}$ (método original), para 24h; esta modificação foi realizada para comparar esta sílica com aquela sintetizada com TEOS.

Figura 1 - Difratogramas de raios-X dos materiais sintetizados.

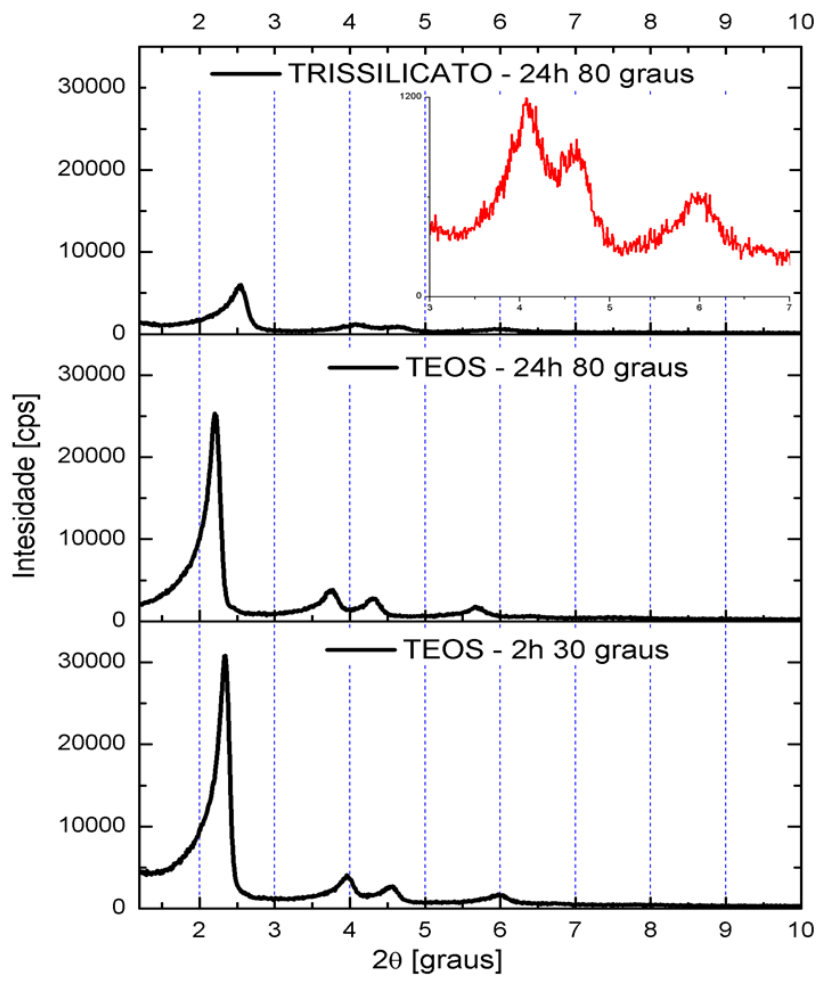

Na Figura 2 é mostrada a avaliação catalítica dos materiais, em termos de conversão de acetato de etila na reação modelo de transesterificação. Em todos os casos verificou-se atividade catalítica semelhante no primeiro uso para os catalisadores sintetizados com TEOS, destacando-se aquele obtido com trissilicato de sódio. A maior atividade catalítica dá indícios de que este material apresenta maior quantidade de material orgânico em sua estrutura, uma vez que esses cátions compensam grupos silóxi, que são os sítios ativos para catálise. Nesse sentido, pode-se também inferir que esse catalisador apresenta menor quantidade de grupos silanóis, o que lhe confere maior estabilidade hidrotérmica (Igarashi, 2003).

Durante o reciclo (avaliação da estabilidade catalítica), ambos materiais apresentaram desativação. O material sintetizado com trissilicato de sódio apresenta maior diminuição da conversão. Este efeito é explicado pela lixiviação dos cátions CTA da estrutura, onde os sítios básicos são protonados pelo álcool presente no meio reacional, diminuindo então a capacidade de conversão dos catalisadores (Fabiano, 2010).

Na Figura 3, são mostrados os difratogramas de raios-X ao final de cada reciclo para todos materiais. Nota-se que para o material sintetizado com TEOS em duas horas de tratamento hidrotérmico apresenta diminuição dos picos; os picos secundários da MCM-41 já 
não são observados após o terceiro uso do material, apesar do material remanescente ser mesoporoso (pico principal presente).

Figura 2 - Conversão de acetato de etila na reação de transesterificação.

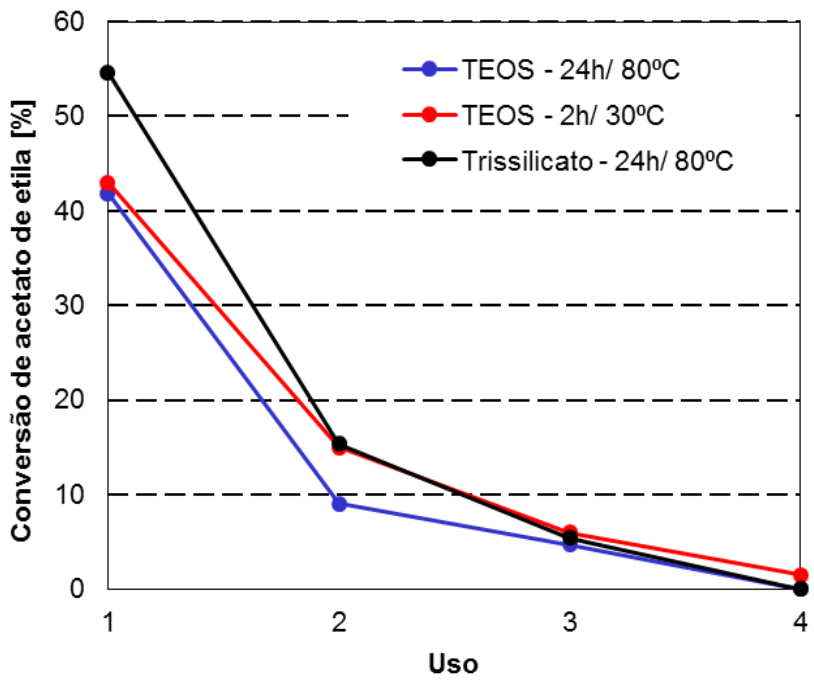

Para o material sintetizado com TEOS, com 24 horas de tratamento hidrotérmico, apesar da diminuição dos picos de difração ao longo do reciclo do catalisador, a fase MCM-41 é persistente, pois inclusive após o final do quarto uso observam-se os picos secundários típicos desse material. Segundo Igarashi (2003), a perda dos picos secundários está ligada a maior quantidade de grupos silanol na estrutura, o que indica estrutura menos condensada e portanto menos estável hidrotermicamente.

Figura 3 - Difratogramas dos catalisadores usados na reação de transesterificação: (a) TEOS 2h 30 graus, (b) TEOS 24h 80 graus e (c) TRISSILICATO 24h 80 graus.
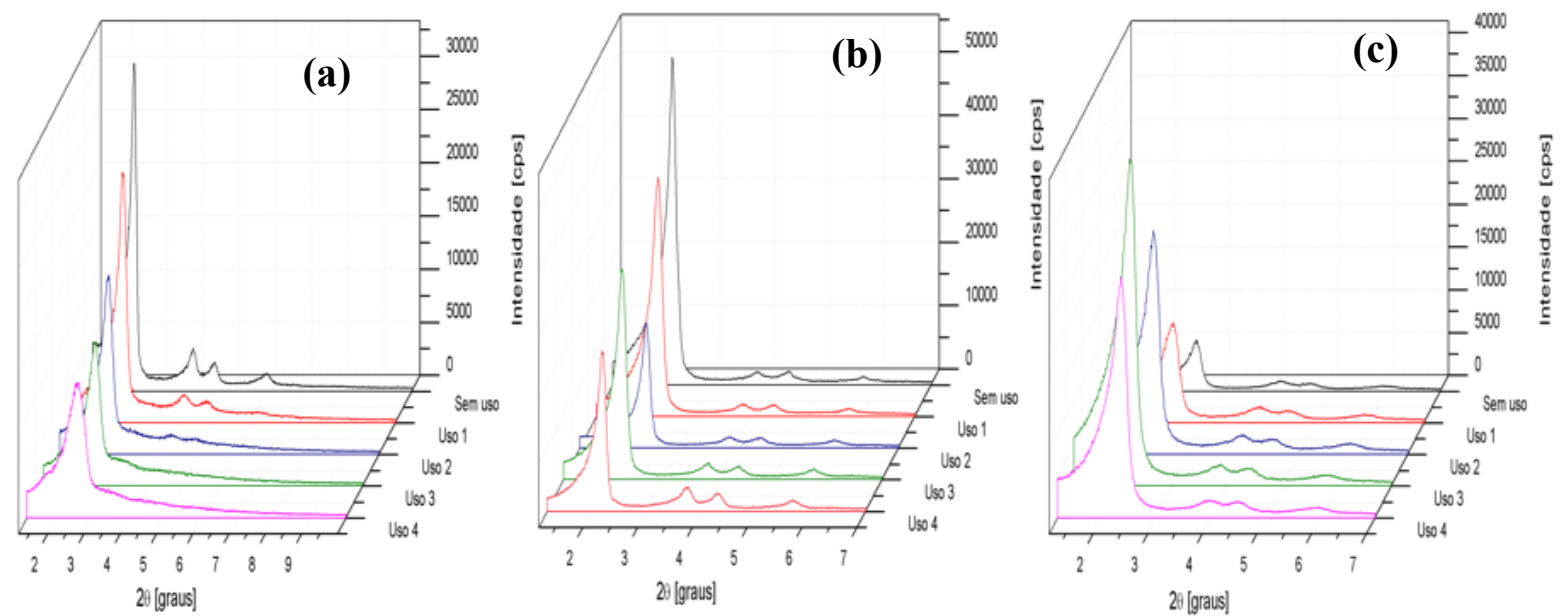

Em contrapartida, para o material sintetizado com trissilicato de sódio, observa-se um aumento dos picos de difração, em todos os casos com fase MCM-41 persistente. Fabiano (2010), explica o aumento dos picos de difração pela saída dos cátions CTA, que 
possivelmente absorvem a radiação $\mathrm{X}$. Apesar de em ambos os casos haver lixiviação dos cátions CTA (Figura 2), quando a temperatura de síntese é maior, menor quantidade de grupos silanóis superficiais, dando maior estabilidade hidrotérmica a MCM-41, como se observada para os materiais sintetizados a $80^{\circ} \mathrm{C}$. Além disso, a fonte de sílica influencia esse comportamento estrutural, como pode-se verificar quando comparados os catalisadores obtidos com TEOS e trissilicato de sódio, numa mesma temperatura e tempo de tratamento hidrotérmico: no primeiro caso ocorre diminuição dos picos de difração e no segundo, aumento. Os resultados apresentados por Igarashi (2003) corroboram com essa observação.

\section{CONCLUSÃO}

Neste trabalho avaliou-se a estabilidade catalítica e estrutural da MCM-41 contendo cátions CTA sintetizada com TEOS e trissilicato de sódio, em transesterificação. O material sintetizado com trissilicato de sódio apresentou maior estabilidade estrutural e catalítica e menor estabilidade catalítica. O material sintetizado com TEOS a maior temperatura e tempo de tratamento hidrotérmico apresentou fase MCM-41 persistente ao longo do reciclo, indicando maior estabilidade da estrutura obtida, enquanto que a MCM-41 sintetizada a duas horas de tratamento hidrotérmico e menor temperatura demonstrou perda dos picos de difração típicos com o reciclo.

\section{REFERÊNCIAS}

GEORGOGIANNI, K.G.; KATSOULIDIS, A.K.; POMONIS, P.J.; MANOS, G.; KONTOMINAS, M.G. Transesterification of rapeseed oil for the production of biodiesel using homogeneous and heterogeneous catalysis. Fuel Proc. Tech., v. 90, p. 1016-1022, 2009.

GÓMEZ, J. M.; ROMERO, M. D.; CALLEJO, V. Heterogeneous basic catalysis for upgrading of biofuels. Catal. Today, v. 218-219, p.143-147, 2013.

FABIANO, D. P.; HAMAD, B.; CARDOSO, D.; ESSAYEM, N. On the understanding of the remarkable activity of template-containing mesoporous molecular sieves in the transesterification of rapeseed oil with ethanol. J. of Catal., v. 276, p. 190-196, 2010.

FABIANO, D. P. Síntese e avaliação de sílica do tipo M41S contendo cátions CTA em transesterificação catalítica. Dissertação (Mestrado em Engenharia Química), 103 f., 2010. Departamento de Engenharia Química - Universidade Federal de São Carlos, São Carlos.

IGARASHI, N.; KOYANO, K. A.; TANAKA, Y.; NAKATA, S.; HASHIMOTO, K.; TATUSMI, T. Investigation of the factors influencing the structural stability of mesoporous silica molecular sieves. Microp. And Mesop Mat., v. 59, p. 43-52, 2003.

SCHUMACHER, K.; GRUN, M.; UNGER, K.K. Novel synthesis of spherical MCM-48. Micropo. And Mesop. Mat., v. 27, p. 201-206, 1999. 
MOKHONOANA, M. P.; COVILLE, N. J. Synthesis of [Si]-MCM-41 from teos and water glass: the water glass-enhanced condensation of teos under alkaline conditions. J. Sol-Gel Sci. Technol., v. 54, p. 83-92, 2010. 